\title{
Correction to: Analysing the Combined Health, Social and Economic Impacts of the Corona Virus Pandemic Using Agent-Based Social Simulation
}

\section{Frank Dignum ${ }^{1}$ D $\cdot$ Virginia Dignum ${ }^{1} \cdot$ Paul Davidsson $^{2} \cdot$ Amineh Ghorbani $^{3}$. Mijke van der Hurk ${ }^{4}$ - Maarten Jensen ${ }^{1}$. Christian Kammler ${ }^{1}$. Fabian Lorig ${ }^{2}$. Luis Gustavo Ludescher ${ }^{1}$. Alexander Melchior ${ }^{4}$. René Mellema ${ }^{1}$. Cezara Pastrav $^{1} \cdot$ Loïs Vanhee $^{5} \cdot$ Harko Verhagen $^{6}$}

Published online: 10 July 2021

(c) Springer Nature B.V. 2021

\section{Correction to: Minds and Machines (2020) 30:177-194 https://doi.org/10.1007/s11023-020-09527-6}

In the original publication, the article title has been mistakenly published online. Now the same has been corrected provided in this correction.

Publisher's Note Springer Nature remains neutral with regard to jurisdictional claims in published maps and institutional affiliations.

The original article can be found online at https://doi.org/10.1007/s11023-020-09527-6.

Frank Dignum

dignum@cs.umu.se

1 Umeå University, Umeå, Sweden

2 Malmö University, Malmö, Sweden

3 TU Delft, Delft, Netherlands

4 Utrecht University, Utrecht, Netherlands

5 University of Caen, Caen, France

6 Stockholm University, Stockholm, Sweden 